\title{
Desmin: molecular interactions and putative functions of the muscle intermediate filament protein
}

M.L. Costa, R. Escaleira, A. Cataldo, F. Oliveira and C.S. Mermelstein
Laboratório de Diferenciação Muscular e Citoesqueleto, Departamento de Histologia e Embriologia, Instituto de Ciências Biomédicas, Universidade Federal do Rio de Janeiro, Rio de Janeiro, RJ, Brasil

\section{Correspondence \\ M.L. Costa \\ Laboratório de Diferenciação \\ Muscular e Citoesqueleto \\ Departamento de Histologia e \\ Embriologia, ICB, UFRJ \\ 21949-590 Rio de Janeiro, RJ \\ Brasil \\ Fax: +55-21-2562-6480 \\ E-mail: manoelluiscosta@ufrj.br \\ Presented at the XII Brazilian \\ Congress of Cellular Biology, \\ Campinas, SP, Brazil, July 15-18, \\ 2004.}

Research supported by CNPq, FAPERJ, PRONEX, and Fundação Universitária José Bonifácio (FUJB).

Received July 16, 2004

Accepted September 14, 2004

\begin{abstract}
Desmin is the intermediate filament (IF) protein occurring exclusively in muscle and endothelial cells. There are other IF proteins in muscle such as nestin, peripherin, and vimentin, besides the ubiquitous lamins, but they are not unique to muscle. Desmin was purified in 1977, the desmin gene was characterized in 1989, and knock-out animals were generated in 1996. Several isoforms have been described. Desmin IFs are present throughout smooth, cardiac and skeletal muscle cells, but can be more concentrated in some particular structures, such as dense bodies, around the nuclei, around the Z-line or in costameres. Desmin is up-regulated in muscle-derived cellular adaptations, including conductive fibers in the heart, electric organs, some myopathies, and experimental treatments with drugs that induce muscle degeneration, like phorbol esters. Many molecules have been reported to associate with desmin, such as other IF proteins (including members of the membrane dystroglycan complex), nebulin, the actin and tubulin binding protein plectin, the molecular motor dynein, the gene regulatory protein MyoD, DNA, the chaperone $\alpha \mathrm{B}$-crystallin, and proteases such as calpain and caspase. Desmin has an important medical role, since it is used as a marker of tumors' origin. More recently, several myopathies have been described, with accumulation of desmin deposits. Yet, after almost 30 years since its identification, the function of desmin is still unclear. Suggested functions include myofibrillogenesis, mechanical support for the muscle, mitochondrial localization, gene expression regulation, and intracellular signaling. This review focuses on the biochemical interactions of desmin, with a discussion of its putative functions.
\end{abstract}

\section{Introduction}

Desmin is the intermediate filament (IF) protein of muscle and endothelial cells. The cytoskeletal category of IFs was suggested by Holtzer's group (1) based on the 10-nm diameter filaments observed in electron mi-
Key words

- Desmin

- Intermediate filaments

- Muscle

- Myogenesis

- Myopathy crographs of skeletal muscle, which were intermediate in diameter between the 5-nm microfilaments and the 16-nm thick filaments. Muscle IF protein was purified by Small and Sobieszek (2) who called it "skeletin", but Lazarides and Hubbard (3), who also purified it, named it "desmin" (desmos = link) 


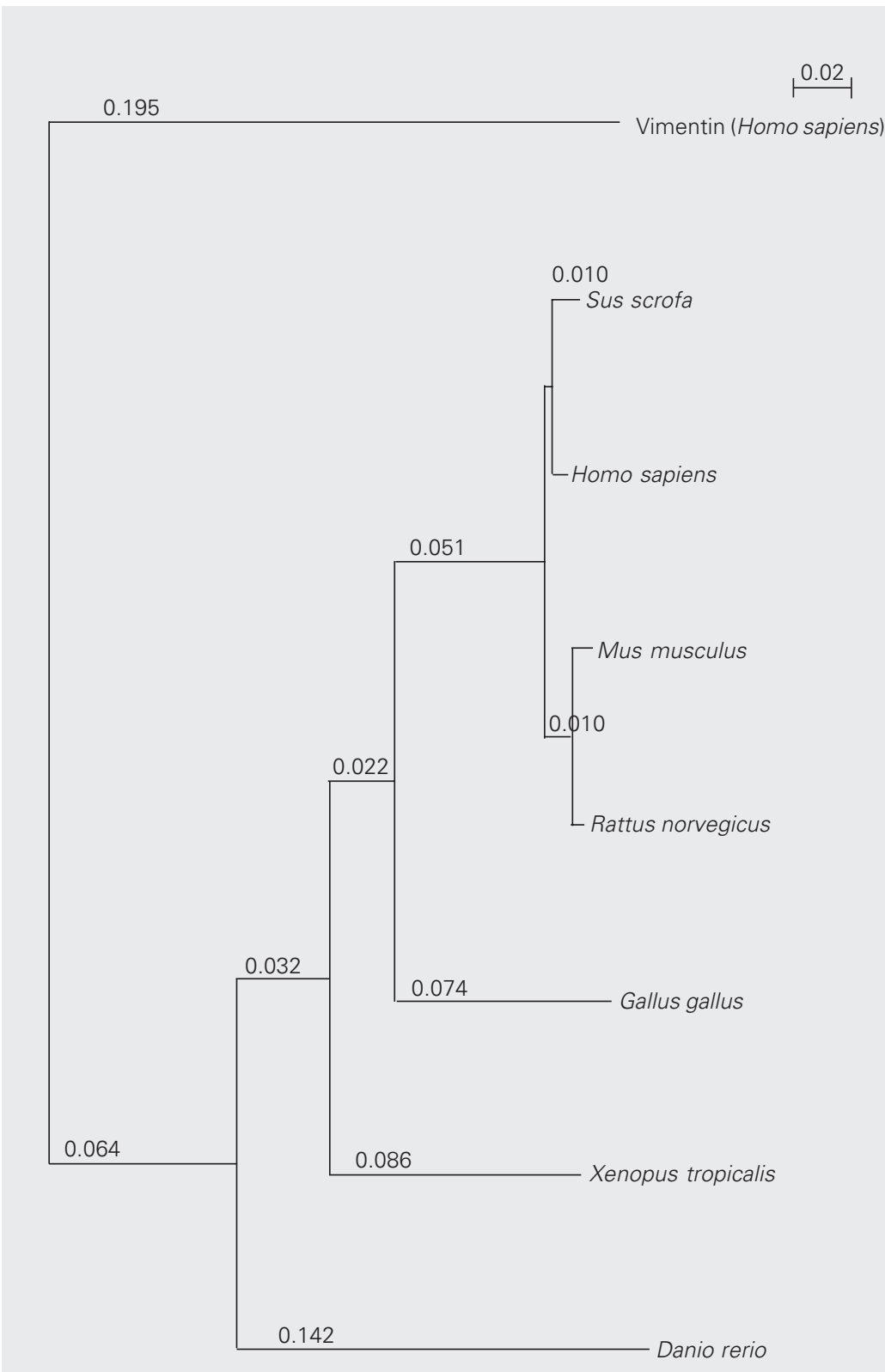

Figure 1. Phylogenetic relationships of desmin from several animals. Multiple sequence alignments were generated following the alignment of the human gene using the CLUSTALX software. The evolutionary tree was prepared with the NIPLOT software. This figure shows that desmin is quite conserved evolutionarily. The changes are very well related to phylogeny (more time of species divergence, more differences among the desmins). This constant rate of evolutionary change over time indicates that desmin should be on a high selective pressure and should have a high adaptive value. The following sequences were obtained from PubMed: 1-gil6686280IDesmin[Homo sapiens], 2-gil 118453IDesmin[Gallus gallus], 3-gil48374063IDesmin[Sus scrofa], 4-gil38197676| Desmin[Rattus norvegicus], 5-gil33563250IDesmin[Mus musculus], 6 gil38511808| Desmin[Xenopus tropicalis], 7-gil18858539IDesmin[Danio rerio], 8-gil4507895IVimentinl [Homo sapiens]. for its alleged function of linking sarcomeres. Biochemical purification led to antibody production, which in turn led to the determination of its spatial distribution in several tissues (4). The gene has been identified by Capetanaki et al. (5), and desmin knockouts have been produced by the groups of Paulin (6) and Capetanaki (7). Desmin has been shown to interact with several molecules, and therefore particular functions for desmin are attributed to each of these interactions. Many aspects of the cell biology of desmin are remarkable, like its resistance to chemical denaturation and mechanical stability, and its direct interaction with the muscular differentiation program. It is the first muscle-specific structural protein and one of the more persistent in several differentiation conditions. The recent finding of several cases of human diseases linked to altered desmin expression (8) has renewed the interest in the physiological roles of desmin. However, despite all the curiosity it inspired, the function of desmin is still unknown.

\section{Biochemical aspects}

Human desmin is a protein of $52 \mathrm{kDa}$, 470 amino acids, with pI 5.4. There is a single desmin gene $(D E S)$ in all vertebrates, with reasonable sequence conservation, since there is great homology between the gene from zebrafish and man, as is shown in the phylogenetical analysis (Figure 1). The DES gene has been sequenced in several animal species, such as man, rat, mouse, cow, pig, hamster, chicken, Xenopus, and zebrafish (9). While only vertebrates express desmin, there are related molecules in other animals. Tunicates have an St-A protein, an intermediate filament protein has been described in C. elegans, lamins have been found in Drosophila, and an intracellular transport protein, with $20 \%$ homology with desmin, was found in Saccharomyces. The desmin protein, like all intermediate filaments, has two conserved central rod domains ( $\mathrm{H} 1$ and $\mathrm{H} 2)$, 
4 linker regions (L1A, L1B, L2A, and L2B), and two globular end domains. The central rod domains are responsible for polymerization by lateral association. The exact structure of the filament is still unclear, but it is known that IF molecules associate laterally in pairs, which in turn associate with each other. The 10-nm filament may be formed by about 8 individual protofilaments (10). In this way, a truncation of the desmin carboxyterminal domain in a few molecules leads to the disassembly of the filament network, when a truncated desmin gene is expressed in a few nuclei in a multinuclear myotube (11).

The central IF domain is composed of several heptapeptide repeats, which form coiled-coil $\alpha$-helices. This domain is present in several protein families from spectrin to plectin. Desmin has also a less conserved IF head domain, and the end domains are overall quite variable among IFs. Sequence homology, and therefore evolutionary relationships, and the ability to co-polymerize are the main criteria for their classification into 6-7 groups (10, but see Ref. 12). Thus, desmin is classified as a type III IF, and shares high homology with mesenchymal cell vimentin and glial cell GFAP (glial fibrillary acidic protein). All type III IFs can form homopolymers with themselves or heteropolymers with each other. The acid and basic cytokeratins of epithelial cells are classified as types I and II, respectively, and they are obligatory heteropolymers between the two classes. The three different neurofilament proteins compose the type IV IF. Type V is defined by the lamins, which are ubiquitous supporters of nuclei in all eukaryotic cell types, and are thought to be the evolutionary more primitive IF protein. Lamins have a nuclear localization signal and an extra domain, which induces the formation of a lattice instead of the conventional filaments. While some classifications propose class VI to be composed of large molecular weight proteins (synemin, paranemin), others suggest type VI to be a special group for lens-beaded filaments (phakinin and filensin) or as an orphan group of unclassified proteins. Several other IF proteins, like peripherin, gelfitin, transitin, tanabin, gliarin, macrolin, etc., have been described, in an ever-growing list. A total of 65 IF genes have been detected in a screening of a draft version of the human genome (13).

Desmin is usually phosphorylated, and the number of isoforms correlates with phylogeny: there is a single isoform in mammalian muscle, 2 in an avian muscle and 3 in fish muscle (Figure 2). As is the case for all IFs, phosphorylation regulates desmin poly-

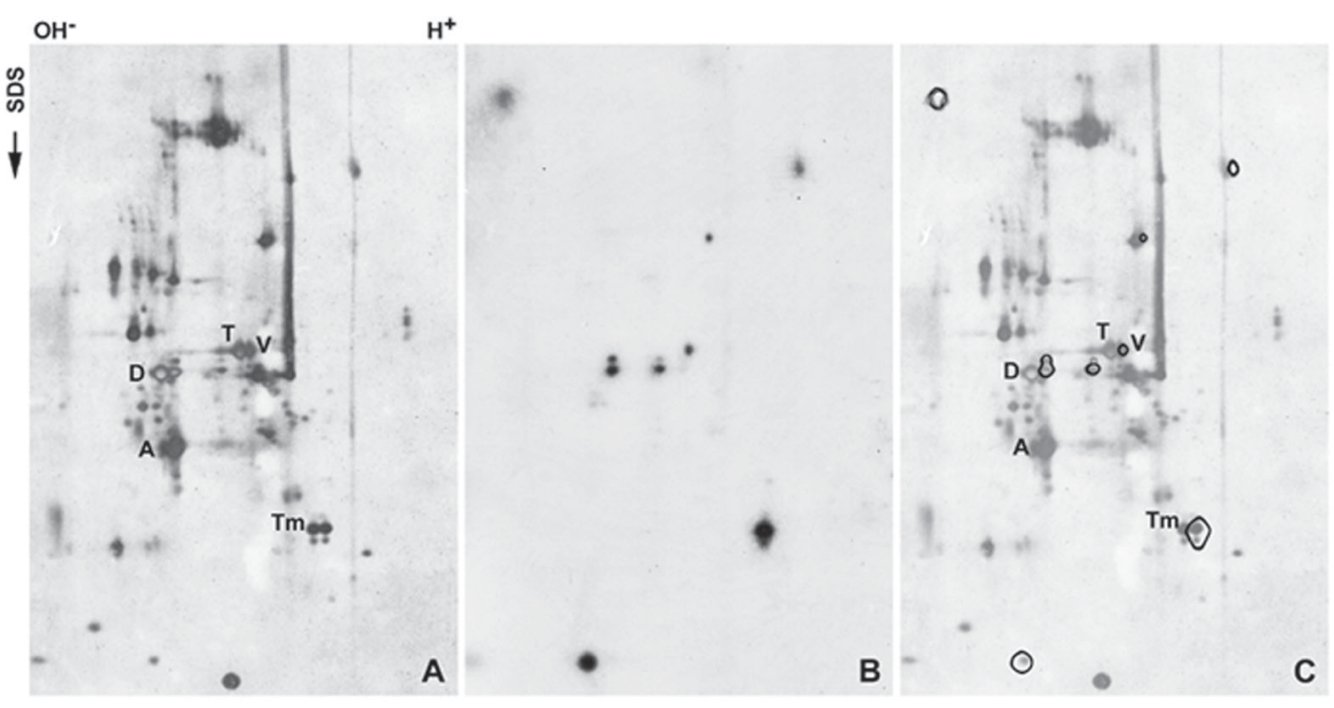

Figure 2. Two-dimensional electrophoresis of an extract of the cytoskeleton of 1-day-old cultured mouse heart cells. A, Proteins detected with silver staining; $B$, corresponding autoradiogram of cells incubated with ${ }^{32} \mathrm{P}$ for $1 \mathrm{~h}$, and $C, A$ and $B$ superimposed, where the image of $B$ has been outlined digitally. After $1 \mathrm{~h}$ of incubation, only a few proteins, particularly desmin, are phosphorylated, while other proteins known to be phosphorylatable, such as actin and tubulin, do not incorporate phosphate. The proteins have been identified by their relative positions as: $\mathrm{D}=$ desmin, $\mathrm{A}=\operatorname{actin}, \mathrm{T}=$ tubulin, $\mathrm{V}=$ vimentin, and $\mathrm{Tm}=$ tropomyosin. Left is basic $\left(\mathrm{OH}^{-}\right)$ and right is acid $\left(\mathrm{H}^{+}\right)$. SDS = sodium dodecyl sulfate. The arrow indicates the second dimension, from high to low molecular weight. For detailed conditions, see Ref. 17. 
merization, so the number of isoforms may correlate with the structural state of each tissue. Signaling molecules like protein kinase $\mathrm{C}$ can increase the phosphorylation of desmin and change the structure of the filament network (14). Interestingly, some particular physiological conditions or pathologic situations can also increase the number of desmin isoforms. Thus, there are 5-6 desmin isoforms in Purkinje fibers, specialized conducting cells in the heart of large mammalians (15). In people with familial congenital heart disease, there are also 5-6 isoforms (16). We could show that there are five desmin isoforms in the electric organs of the electric eel Electrophorus electricus L. (17). Furthermore, our group showed that each of the three different electric organs of the electric eel has a distinct desmin isoform pattern (18). All of these muscle derivatives also have a higher IF to myofibril ratio than normal muscle.

\section{Myogenesis}

Desmin is expressed since the early formation of skeletal, cardiac and smooth muscle, and endothelial cells. In avian cells, desmin is the first muscle-specific cytoskeletal protein or isoform to be expressed, after (or together with) the commitment of precursor cells to the muscle lineage. During embryonic development, the notochord secretes the inductive factors $\mathrm{SHH}$, the neural plate secretes Wnt and the lateral plate secretes BMP4, which will cause the somite cells to become committed to the muscle lineage. These proteins induce the expression of the muscle regulator factor Myf5, which in turn will induce MyoD, which will induce mgn. The genes of most of the structural muscle proteins have a MyoD-binding regulation region. Desmin has been reported to be expressed in muscle together with Myf5 and before MyoD (19). The detection of desmin inside the nucleus and the finding that desmin can form a dimer with MyoD are very intri- guing (see below). The direct relationship between desmin expression and muscle differentiation is difficult to establish, since muscle cells can develop without desmin $(6,7)$, but muscle can also form in the absence of MyoD or mgn (but not of MyoD and mgn). In chick, muscle-committed cells exit the cell cycle, and the forced expression of MyoD shows a coordinated beginning of desmin expression and inhibition of 5-bromo2 '-deoxyuridine labeling (20). In mice, replicating muscle cells express desmin (21). It should be pointed that those two models have quite different in vitro behavior, because mammalian cells replicate more easily and form small myotubes in culture, while avian cells stop replicating and form enormous and vigorously contracting myotubes. While there are several mammalian muscle cell lines, no well-differentiated avian muscle lines have been established (the main avian muscle line QM7 does not form myotubes).

The subcellular distribution of desmin changes during development from thick filaments widespread throughout the cell to a diffuse association with the Z-line and striation. It should be noted that the mesenchymal precursors of muscle cells already have a vimentin IF network. Accordingly, this change in distribution is a marker of myogenesis, which we used to characterize the extent of MyoD conversion in transfected non-muscle chick cultured cells (20) and to point out the particularities of the myogenesis in zebrafish embryos (22).

\section{Cellular distribution}

The best way to visualize the distribution of desmin in different cell types is by immunofluorescence (Figure 3). Desmin appears sometimes as long isolated filaments, but it also appears as a fluorescence haze, probably because of its sub-resolution size (10 $\mathrm{nm}$, smaller than the $0.2-\mu \mathrm{m}$ light microscope limit).

Desmin has been described in almost 
every distinct muscular cytoskeletal structure (Figure 4). In mononucleated smooth muscle cells, desmin is spread throughout the cell, but is concentrated in the dense bodies (Figure 4, a), where the microfilaments also attach. Dense bodies are centers of contraction, and have $\alpha$-actinin and actin beside desmin, being homologues to Z-lines and intercalated disks (23). Desmin can make up to $2 \%$ of the smooth muscle mass, and chicken gizzard is commonly used for desmin extraction.
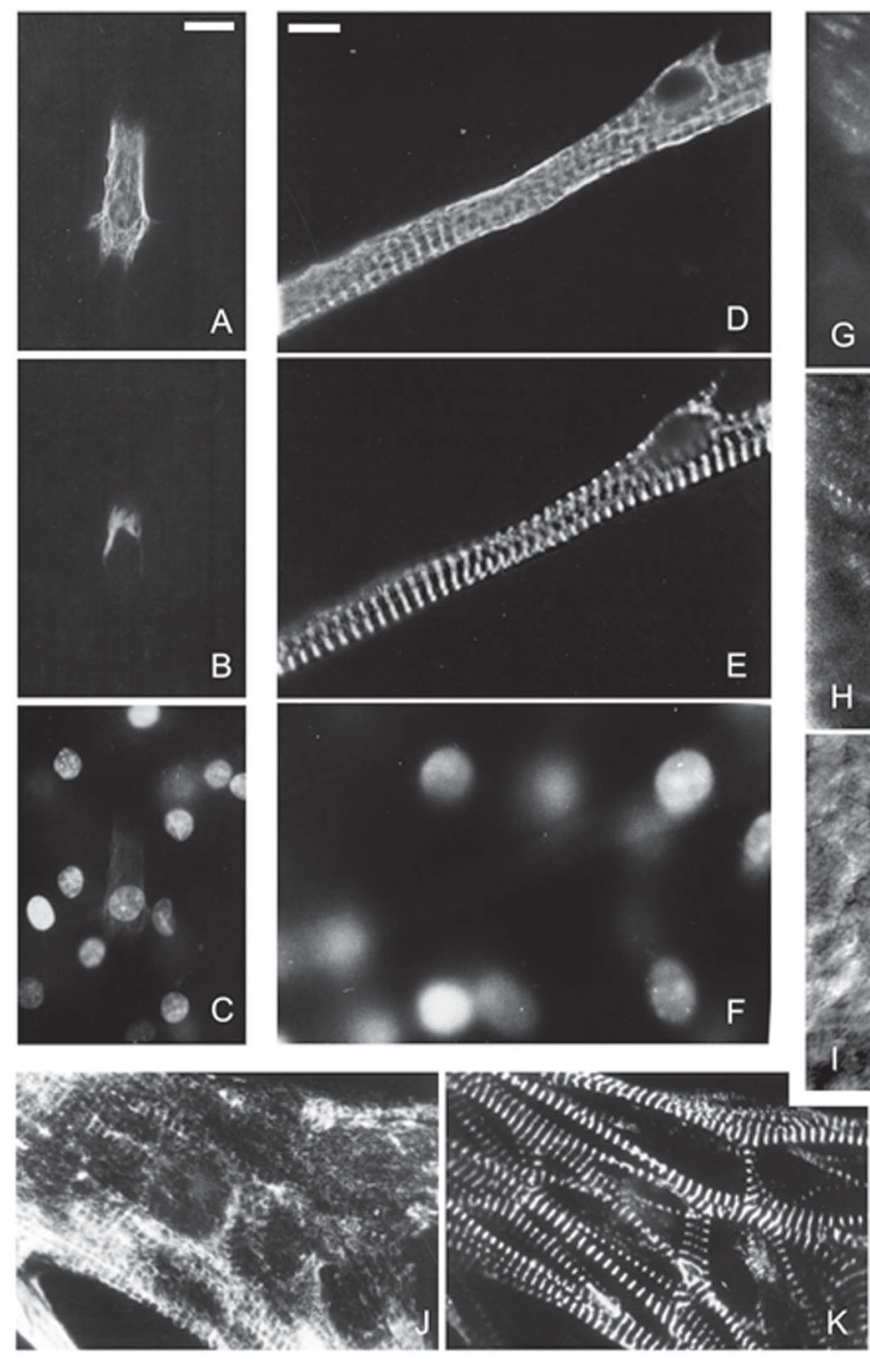
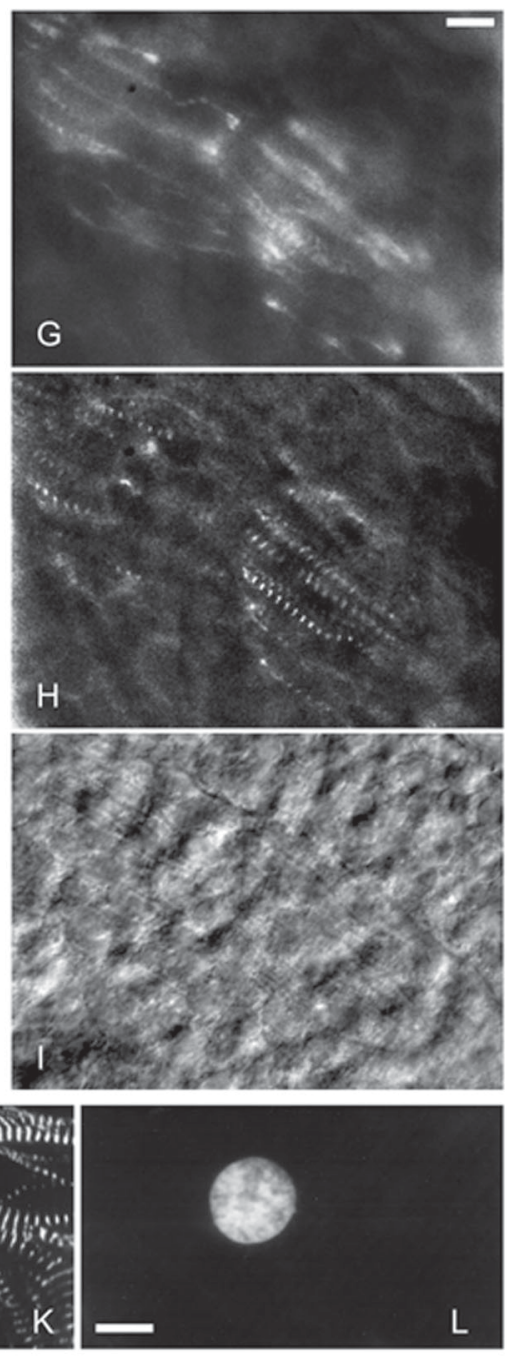

Figure 3. Desmin distribution in several cell types detected by immunofluorescence. One-day-old cultured skeletal muscle chick cell, stained for desmin (A), myosin (B) and DNA (4',6-diamidino-2-phenylindole dihydrochloride) (C). At this developmental stage, myoblasts are beginning to elongate, desmin is distributed throughout the cytoplasm, and myosin appears first around the nucleus. Five-day-old cultured skeletal muscle chick myoblast stained for desmin (D), Z-line titin (E) and DNA (F). This myoblast is already striated for desmin and titin. Desmin is present on the Z-line, but not as restricted as titin. There is also desmin around the nuclei and diffusely in the cytoplasm. Twenty-four-hour zebrafish somites stained for desmin (G), $\alpha$-actinin (H) and differential interference contrast (I). These 2-hour-old myocytes in the fish embryo show a pattern similar to the 5-day chicken culture, with striations visible by desmin and $\alpha$-actinin stain and by differential interference contrast. Three-day-old cultured heart chick cell stained for desmin (J), $\alpha$-actinin $(K)$ and DNA (L). In cardiac myocytes, desmin distribution on the Z-line is more restricted than in skeletal muscle, but there is also more desmin in the cytoplasm. The myofibrils are not aligned as in skeletal muscle, as can be seen by the $\alpha$-actinin stain. Scale bar: $10 \mu \mathrm{m}$ for all panels. For details, see Refs. 22 and 57. 
In the multinucleated striated skeletal muscle, again there is desmin all over the cell, but there is more desmin in the Z-line (lateral attachments of microfilaments; Figures $3 \mathrm{D}, \mathrm{G}, \mathrm{J}$ and $4, \mathrm{~b}$ ) and in the costameres (periodic structures in the membrane that are connected to the Z-lines, Figure 4, c). Costameres are composed of several protein clusters and link IFs and actin microfilaments to the membrane (24). One type of costamere, the dystroglycan protein complex (DPC), connects actin through dystrophin to the transmembrane $\beta$-dystroglycan, which in turn binds to extracellular $\alpha$-dystroglycan, laminin 2 and collagen. Another type of protein complex connects actin through spectrin, talin, paxillin, and vinculin to trans-membrane integrins, which bind to fibronectin, laminin and collagen. Desmin connects to DPC in the costameres, through plectin and dysferlin. The DPC alterations cause Duchenne and Becker muscular dystrophies, frequent congenital diseases that can be fatal. In skeletal muscle, desmin has been described in myotendinous junctions, together with nestin (Figure 4, d) (25), and in

\section{Smooth muscle}
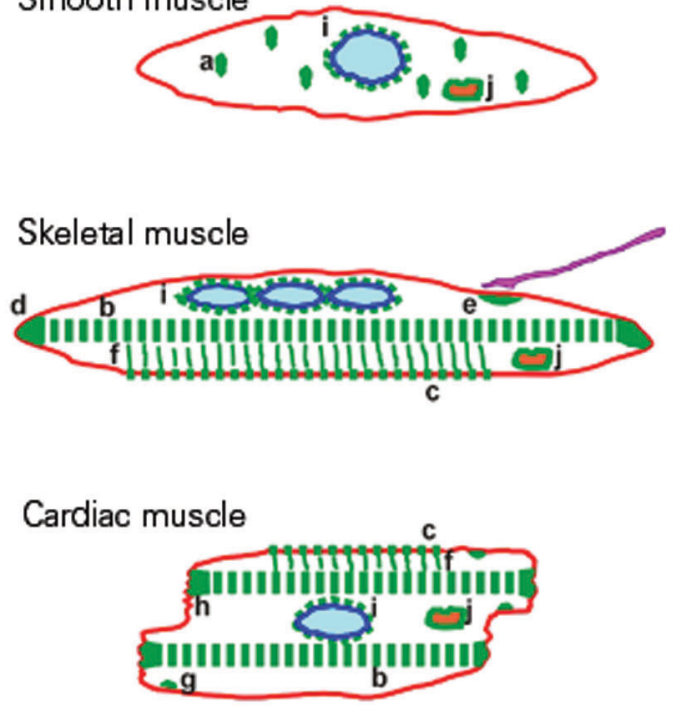

Figure 4. Location of desmin in smooth, skeletal and cardiac muscle types. $a$, Dense bodies; $b$, sarcomeres; $c$, costameres; $d$, myotendinous junction; $e$, neuromuscular junction; $f$, extra-myofibrillar cytoskeleton; $g$, desmosomes; $h$, intercalated disk; $i$, perinuclear position; j, mitochondria. neuromuscular junctions, associated with the cholinergic receptors (Figure 4, e) (26). Myotendinous junctions are specialized regions of skeletal muscle attachment to connective tissue, and have characteristic molecules, such as type XII and XIII collagens and $\alpha 7$ integrin. The neuromuscular junctions mediate the contraction stimulus through chemical signaling between acetylcholine releasing nerve cells and the cholinergic receptors in the synapse, a special membrane region with clefts (invaginations) and particular constituents, like type XVIII collagen and agrin. Desmin may also be present around the Mline, particularly associated with skelemin (see below). Desmin also connects myofibrils to the costameres, forming an extramyofibrillar cytoskeleton (Figure 4, f).

Heart cells are mono- or binucleated and have desmosomes, where the IFs of neighbor cells are connected through cadherins and cytokeratin (Figure 4, g). Desmosomes are typical of strongly attached epithelial cells, and are composed of desmoplakin agglomerates that bind transmembrane cadherins in adjacent cells (27). In cardiac cells, desmosomes bind myocytes laterally, while the myofibrils of each cell end in a special Zline that attaches to adjacent cells, the intercalated disk (Figure 4, h). Therefore, desmin and $\alpha$-actinin are present in all the contraction organizing centers in the three muscle cell types. The distribution of both proteins is mostly coincident, but clearly is not restricted to the same places. In non-muscle cells, $\alpha$-actinin is distributed along actin filaments and links them to the membrane, and in striated muscle, $\alpha$-actinin aggregates on the membrane could be nucleating centers for myofibrillogenesis. Heart cells have the highest proportion of desmin and also a large number of mitochondria.

Desmin, like all IFs, is also concentrated around the nucleus (Figure 4, i) in the three muscle types. In muscle cell fractionation experiments, desmin has been found to remain bound to the nuclear fraction (data not 
shown). Furthermore, there is a direct interaction between cytoplasmic IFs and the nuclear lamins (28). Interestingly, the muscle nuclear envelope has a particular lamin-associated protein, emerin, which was identified as missing in people with Emery-Dreifuss muscular dystrophy (29). It is possible to speculate that the muscle nuclei should have a particular structure to withstand the mechanical load of contraction, in the same way as the desmin network could be unique. Mutations in the lamin A gene in humans are also responsible for muscular dystrophy, and knock-out for lamin A induces the muscular dystrophy phenotype (30). Because lamin A is present in several cell types and only muscles are affected by its absence, muscle nuclei could be subjected to a greater mechanical stress than other cell types.

Mitochondria are somehow connected to desmin IFs in addition to microtubules (Figure $4, \mathrm{j}$ ).

\section{Molecular interactions}

Desmin interacts with several molecules (Table 1). First of all, it forms heteropolymers with IF proteins of the same class, like vimentin, GFAP, nestin, etc., which may coexist in some cell types, and with type VI IF proteins. The other IF proteins that may copolymerize with desmin in vitro will not be considered in this review. While vimentin is co-expressed in vivo, it is down-regulated along myogenesis, and almost not present in adult tissues. The exact amount of vimentin protein present in adult tissues is still unclear, but specific silencer regulatory sequences have been identified in the gene (31). GFAP can polymerize with desmin in

Table 1. Macromolecules that interact with desmin

\begin{tabular}{|c|c|c|c|}
\hline & Refs. & Distribution & Also links to \\
\hline Vimentin & 28 & At the periphery of Z-discs & Type III or VI IFs \\
\hline GFAP & 32 & In myofibroblasts & Type III or VI IFs \\
\hline Nestin & 12,33 & In myotendinous junctions & Type III or VI IFs \\
\hline Synemin & $34-36,40$ & $\begin{array}{l}\text { At the periphery of the Z-line and in } \\
\text { the sarcolemma of costameres }\end{array}$ & $\begin{array}{l}\text { Type III or VI IFs. } \alpha \text {-actinin, } \\
\text { vinculin, plectin }\end{array}$ \\
\hline Paranemin & 37,38 & $\begin{array}{l}\text { At the periphery of the Z-line and in the sarcolemma } \\
\text { and myotendinous and neuromuscular junctions }\end{array}$ & Type III or VI IFs, plectin \\
\hline Desmuslin & 39 & $\begin{array}{l}\text { At the periphery of the Z-line and in the sarcolemma } \\
\text { of costameres }\end{array}$ & $\begin{array}{l}\text { Dystrophin, } \alpha 1 \text {-syntrophin, sarcoglycans, } \\
\alpha \text {-dystrobrevin, plectin }\end{array}$ \\
\hline Syncoilin & 41 & In costameres and in neuromuscular junctions & $\alpha$-dystrobrevin \\
\hline Lamins & 28 & In the nucleus & $\alpha \mathrm{B}$-crystallin, emerin, nesprin, actin, DNA \\
\hline Nebulin & 43 & On the Z-line & Actin, titin, $\alpha$-actinin, myosin \\
\hline Skelemin & 44 & In the M-disc & Integrin \\
\hline Spectrin, ankyrin & 42 & $\begin{array}{l}\text { At the periphery of the Z-line and in myotendinous and } \\
\text { neuromuscular junctions }\end{array}$ & Ankyrin, spectrin \\
\hline Plectin & 45 & $\begin{array}{l}\text { At the periphery of the Z-line and in myotendinous and } \\
\text { neuromuscular junctions }\end{array}$ & $\begin{array}{l}\text { Myosin II, integrin } ß-4 \text {, actin, spectrin, MAP, } \\
\text { type III or VI IFs }\end{array}$ \\
\hline Dynein & 46 & Along microtubules & Tubulin \\
\hline MyoD & 47 & In the nucleus & Id, Mef \\
\hline DNA & 48 & In the nucleus & Histones, polymerases \\
\hline$\alpha \mathrm{B}$-crystallin & 49 & On the Z-line & Caspases, lamins \\
\hline Calpain, caspase & 50,51 & Desmin as substrate during apoptosis & Lamins, $\alpha$ B-crystallin \\
\hline
\end{tabular}

IF = intermediate filament; GFAP = glial fibrillary acidic protein; MAP = microtubule-associated protein; Mef = muscle enhancer factor 
vitro, but only a few cell types actually coexpress both proteins at the same time. One interesting case is the dynamic and developmentally plastic myofibroblast, which we showed to be positive for desmin, GFAP and vimentin (32). Nestin is typical of central nervous system stem cells, but is also present with desmin in muscle ligaments (33). Since there is a relationship between the expression of nestin and the aggressiveness of tumors, nestin has been an important marker in cancer research. Synemin, initially purified as a desmin-associated molecule (34) but now known to be a legitimate type III or VI intermediate filament, is present in striated muscle. Synemin may function to directly link muscle cell intermediate filaments to both myofibrillar Z-lines and costameres, since it has binding sites for desmin, $\alpha$ actinin and vinculin (35). Curiously, synemin is expressed in all muscle tissues (although at higher levels in skeletal muscle), but also in other tissues, particularly in myoepithelial cells and glial cells (36). Paranemin was also initially described as an IF-associated protein (37), but later was shown to be a type VI large IF protein. Paranemin, but not synemin or nestin, has been shown to be essential for the formation of an extended desmin IF network (38). Desmuslin is an IF protein recently characterized from the dystrophin complex that associates with $\alpha$-dystrobrevin in costameres and with desmin in costameres and around the Z-line (39). But sequence homology suggests that desmuslin may be the human homologue of synemin, more specifically of the smaller synemin $\beta$ transcript (40). Syncoilin is another dystrophinassociated protein that seems to concentrate in neuromuscular junctions (41). Interestingly, nestin, desmuslin and syncoilin are not type III filaments: while nestin may be classified as type IV, desmuslin has been proposed to be a type VI or VII, and syncoilin could be a type IV, since it can form filaments by itself. Desmin may associate with lamins, as mentioned before.
Besides IF proteins, desmin also binds to other sarcomeric and sub-membrane proteins. The extra-myofibrillar desmin cytoskeleton links to the membrane adhesion complexes indirectly through syncoilin and desmuslin/synemin, but there is a direct association between desmin and the proteins spectrin and ankyrin (42). A direct interaction between desmin and nebulin was shown using a yeast two-hybrid approach (43). Nebulin is a molecular ruler that controls the size of the A-band through its binding to actin. Desmin binds to skelemin around the M-line (44). The proposed structure of skelemin has internal myosin-binding regions and two desmin-binding regions, one in each extremity. In this way, desmin binds both to the Z- and M-lines.

The three major filaments of the cytoskeleton are linked by the protein plectin, which has been shown to bind to microtubules, microfilaments and IFs (45). Plectin is a member of the plakin family of cytolinkers, which include the desmosomal desmoplakin, and which also bind to integrins and cadherins. The distribution of plectin is not affected in desmin knock-out mice, but in plectin knock-out mice the amounts of vinculin and spectrin are reduced. IFs seem to be transported throughout the cell associated with microtubules and/or microfilaments via cytoplasmic dynein (46).

Desmin can be present in the nucleus, where it has been suggested to bind to MyoD to form a heterodimeric gene regulation protein (47). The interaction of desmin with MyoD establishes a new self-regulatory pathway, because the MyoD gene has E-boxes, regulatory sequences, MyoD binding sites, as does the desmin gene. Inside the nucleus, desmin can bind directly to DNA. The interaction of type III IFs (vimentin in particular) with several DNA arrangements has been well characterized, and all type III filaments have the same DNA-binding domain (48).

The desmin IF network is dependent on binding to the small chaperone $\alpha \mathrm{B}$-crystallin 
(49). First identified as a structural protein in the eye lens, $\alpha \mathrm{B}$-crystallin is known to exist in several cell types. Other crystallin isoforms also have dual enzymatic and structural roles.

The proteases calpain and caspase can interact with desmin during differentiation and particularly in apoptosis. Caspase 6 phosphorylates specific residues in desmin, induced by change in serum concentration that controls differentiation (50). Desmin has been described as a major substrate for proteolysis by a muscle-specific calpain (51).

\section{Desminopathies}

Since the IF proteins are cell type specific, they have been used to type the origin of undifferentiated cells in tumors or other cells of unknown origin, like electrocytes (17).

The first identified involvement of desmin in human diseases was a familial cardiomyopathy that had filament deposits (15). The advances in molecular diagnosis led to the identification of desmin-related myopathies (52). Their symptoms include skeletal muscle weakness, arrhythmias, heart failure, and accumulation of desmin in cardiac and skeletal muscle cells. The desmin accumulation can be caused by desmin mutations or mutations in $\alpha \mathrm{B}$-crystallin. Several mutations from different families have been characterized. This type of disease has been called surplus myopathy because it arises not from the absence of the protein but from its accumulation due to misaggregation caused by the inability to polymerize properly or by the lack of chaperones ( $\alpha \mathrm{B}$-crystallin), or by its overexpression caused by problems in recycling proteins (caspase, calpain). Experimentally, a small overexpression of desmin does not lead do any damage, but a significant overexpression leads to accumulation of desmin and the formation of aggregates inside the cell, typical of human desminopathy patients. It is still unclear if the accumulation is the cause or the consequence of the disease, which can affect health to varying extents.

\section{Putative functions}

Many functions have been attributed to desmin since its identification. Some can be classified as mechanical or structural, with a role being attributed to the filament itself, but some hypotheses propose that desmin has regulatory roles.

Desmin IFs have been proposed to be required for myofibrillogenesis. Several lines of evidence argue against this hypothesis, including the fact that desmin knock-out mice go through their myogenesis basically unaffected $(6,7)$ and that cells without the IF network caused by transfection with truncated desmin also assemble their myofibrils perfectly (11). By contrast, electroporation of desmin antibodies disrupts the Z-line and the myofibril (53).

Desmin could be involved in the regulation of gene expression. In this case, the main argument is the ability of desmin to bind DNA and its cellular distribution from the cell periphery into the nucleus, where it can interact with lamins $(28,54)$. The nuclear lamins, once thought to be involved only in the mechanical support of the nuclear membrane, now are also suspected to have regulatory functions because of their associations with DNA transcription proteins (55).

Desmin function could be the localization of mitochondria. Desmin knock-out mice have their mitochondria displaced, and these alterations could lead to a deficiency in oxygen metabolism (56). It is noteworthy that these changes in mitochondrial distribution happen before other disturbances.

Desmin, like most IFs, could support and position the nucleus, together with microtubules. After the myoblasts fuse in skeletal muscle, there is an important realignment of the nuclei. Desmin knock-out mice have misplaced nuclei $(6,7)$. We could show in primary chick myogenic cultures that, upon treatment with the phorbol ester 12-O-tetradecanoyl 
phorbol 13-acetate, desmin is phosphorylated, the myofibrils disassemble but the IF network persists, and the nuclei are clustered together in the center (57). Our recent results show that cholesterol withdrawal with the drug methylbeta-cyclodextrin also induces nucleus misalignment (58).

Desmin could be responsible for the elastic properties of muscle, like resistance to stretch. This assumption originated before the identification of the elastic protein titin, which binds the Z- to the M-line. Furthermore, desmin knock-out muscles show the same passive elastic properties as control muscles (59).

While the function of desmin is still uncertain, the same is not true for other IFs and their proteins in other cell types. Thus, it is clear that cytokeratins have a structural role in epithelia because there is a skin blister phenotype both in the cytokeratin knock-out mouse and in the equivalent human disease, epidermolysis bullosa (60). On the other hand, vimentin knock-out mice do not show any greatly altered phenotype (61) and there are no known vimentin-related diseases. One possibility is that IFs perform different functions in specific tissues, and that some of them have structural roles while others have regulatory roles. If this is true, the trend initiated by Holtzer (1) of integrating all the intermediate filaments and their proteins in a single cytoskeletal entity should be reversed by an approach where the differences, more than the similarities, of each filament should be emphasized.

Microfilaments and microtubules have a monotone basic structure of conserved globular molecules in all cells, but they perform several different functions because of their greatly varied associated proteins. IFs have a dual structure, with a central conserved domain and varied terminal domains. We could imagine that the conserved domain is analogous to the basic actin and tubulin blocks, while the varied domains would function to give their cell type specific functions. Not only may the IFs in each cell type have different functions, but they could perform specific functions even in different places in the cell. There are several actin-containing compartments in one cell, each with different properties, as there are different microtubule populations. It is possible, for instance, that the sub-sarcolemmal desmin has a somewhat different function than the nuclear desmin. But in the case of microfilaments and microtubules, the associated proteins are different in each sub-cellular structure. Therefore, we can imagine that each desmin structure is different, maybe because of different associated molecules (such as nestin in myotendinous junctions) or even because of filament arrangement or isoform composition.

If there are many "sub-functions" of desmin, it is reasonable to assume that desmin may have (some) different roles in skeletal, cardiac and smooth muscle. Muscles are an extreme adaptation of a ubiquitous cytoskeleton for force production, and the existence of three main muscle types indicates quite different adaptive solutions, consistent with restricted distributions of some desmin-interacting molecules to each particular muscle type. However, the overall association of desmin with the muscular program is clearcut, because all vertebrate muscles express desmin from their differentiation to all possible adaptations.

The mechanical and physiological functions of microfilaments and microtubules are not exclusive. Focal contacts are sites of strong adhesion to the substrate and of signaling through kinases. Likewise, desmin could have concomitant structural and regulatory roles. In this way, it will be impossible to look for a single function for desmin, and all the mentioned functions could be true.

\section{Acknowledgments}

We would like to thank Profs. Radovan Borojevic, Cristiano Coutinho (UFRJ) and Hernandes Carvalho (UNICAMP) for help and encouragement. 


\section{References}

1. Ishikawa H, Bischoff $R$ \& Holtzer $H$ (1968). Mitosis and intermediate-sized filaments in developing skeletal muscle. Journal of Cell Biology, 38: 538-555.

2. Small JV \& Sobieszek A (1977). Studies on the function and composition of the 10-NM(100-A) filaments of vertebrate smooth muscle. Journal of Cell Science, 23: 243-268.

3. Lazarides E \& Hubbard BD (1976). Immunological characterization of the subunit of the $100 \mathrm{~A}$ filaments from muscle cells. Proceedings of the National Academy of Sciences, USA, 73: 4344-4348.

4. Lazarides E (1980). Intermediate filaments as mechanical integrators of cellular space. Nature, 283: 249-256.

5. Capetanaki YG, Ngai J \& Lazarides E (1984). Characterization and regulation in the expression of a gene coding for the intermediate filament protein desmin. Proceedings of the National Academy of Sciences, USA, 81: 6909-6913.

6. Li Z, Mericskay M, Agbulut O, Butler-Borwne G, Carlsson L, Thornell L-E, Babinet C \& Paulin D (1997). Desmin is essential for the tensile strength and integrity of myofibrils but not for myogenic commitment, differentiation, and fusion of skeletal muscle. Journal of Cell Biology, 139: 1-16.

7. Milner DJ, Waltzer G, Tran D, Bradley A \& Capetanaki Y (1996). Disruption of muscle architecture and myocardial degeneration in mice lacking desmin. Journal of Cell Biology, 134: 1255-1270.

8. Carlsson L \& Thornell LE (2001). Desmin-related myopathies in mice and man. Acta Physiologica Scandinavica, 171: 341-348.

9. Strelkov SV, Herrmann H \& Aebi U (2003) Molecular architecture of intermediate filaments. Bioassays, 25: 243-251.

10. Herrmann H \& Aebi $U$ (2000). Intermediate filaments and their associates: multi-talented structural elements specifying cytoarchitecture and cytodynamics. Current Opinion in Cell Biology, 12: 7990.

11. Schultheiss $T$, Lin ZX, Ishikawa H, Zamir I, Stoeckert CJ \& Holtzer H (1991). Desmin/vimentin intermediate filaments are dispensable for many aspects of myogenesis. Journal of Cell Biology, 114: 953-966.

12. Steinert PM, Chou YH, Prahlad V, Parry DA, Marekov LN, Wu KC, Jang SI \& Goldman RD (1999). A high molecular weight intermediate filament-associated protein in BHK-21 cells is nestin, a type $\mathrm{VI}$ intermediate filament protein. Limited co-assembly in vitro to form heteropolymers with type III vimentin and type IV alpha-internexin. Journal of Biological Chemistry, 274: 9881-9890.

13. Hesse M, Magin TM \& Weber K (2001). Genes for intermediate filament proteins and the draft sequence of the human genome: novel keratin genes and a surprisingly high number of pseudogenes related to keratin genes 8 and 18. Journal of Cell Science, 114: 2569-2575.

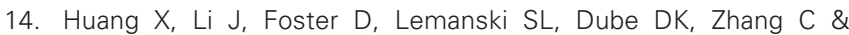
Lemanski LF (2002). Protein kinase C-mediated desmin phosphorylation is related to myofibril disarray in cardiomyopathic hamster heart. Experimental Biology and Medicine, 227: 1039-1046.

15. Thornell LE \& Eriksson A (1981). Filament systems in the Purkinje fibers of the heart. American Journal of Physiology, 241: H291H305.

16. Rappaport L, Contard F, Samuel JL, Delcayre C, Marotte F, Tome F \& Fardeau M (1988). Storage of phosphorylated desmin in a familial myopathy. Federation of European Biochemical Societies. Letters, 231: 421-425.

17. Costa ML, Moura Neto V \& Chagas C (1988). Desmin heterogeneity in the main electric organ of Electrophorus electricus. Biochimie, 70: 783-789.
18. Costa ML, Mermelstein CS, Froes MM, Chagas C \& Moura Neto V (1988). Differences in the isodesmin pattern between the electric organs of Electrophorus electricus L. Comparative Biochemistry and Physiology. Part B, Biochemistry and Molecular Biology, 119: 715-719.

19. Li H \& Capetanaki $Y$ (1993). Regulation of the mouse desmin gene: transactivated by MyoD, myogenin, MRF4 and Myf5. Nucleic Acids Research, 21: 335-343.

20. Choi J, Costa ML, Mermelstein CS, Chagas C, Holtzer S \& Holtzer H (1990). MyoD converts primary dermal fibroblasts, chondroblasts, smooth muscle, and retinal pigmented epithelial cells into striated mononucleated myoblasts and multinucleated myotubes. Proceedings of the National Academy of Sciences, USA, 87: 7988-7992.

21. Kaufman SJ \& Foster RF (1988). Replicating myoblasts express a muscle-specific phenotype. Proceedings of the National Academy of Sciences, USA, 85: 9606-9610.

22. Costa MC, Escaleira RC, Rodrigues VB, Manasfi M \& Mermelstein CS (2001). Some distinctive features of zebrafish myogenesis based on unexpected distributions of the muscle cytoskeletal proteins actin, myosin, desmin, $\alpha$-actinin, troponin and titin. Mechanisms of Development, 116: 95-104.

23. Stromer MH \& Bendayan M (1988). Arrangement of desmin intermediate filaments in smooth muscle cells as shown by high-resolution immunocytochemistry. Cell Motility and the Cytoskeleton, 11: 117-125.

24. Ervasti JM (2003). Costameres: the Achilles' heel of Herculean muscle. Journal of Biological Chemistry, 278: 13591-13594.

25. Tidball JG (1992). Desmin at myotendinous junctions. Experimental Cell Research, 199: 206-212.

26. Mitsui $T$, Kawajiri $M$, Kunishige $M$, Endo $T$, Akaike $M$, Aki $K$ \& Matsumoto $T$ (2000). Functional association between nicotinic acetylcholine receptor and sarcomeric proteins via actin and desmin filaments. Journal of Cellular Biochemistry, 77: 584-595.

27. Tokuyasu KT, Dutton AH \& Singer SJ (1983). Immunoelectron microscopic studies of desmin (skeletin) localization and intermediate filament organization in chicken cardiac muscle. Journal of Cell Biology, 96: 1736-1742.

28. Cartaud A, Jasmin BJ, Changeux JP \& Cartaud J (1995). Direct involvement of a lamin-B-related ( $54 \mathrm{kDa}$ ) protein in the association of intermediate filaments with the postsynaptic membrane of the Torpedo marmorata electrocyte. Journal of Cell Science, 108: 153-160.

29. Holaska JM, Wilson KL \& Mansharamani M (2002). The nuclear envelope, lamins and nuclear assembly. Current Opinion in Cell Biology, 14: 357-364.

30. Sullivan T, Escalante-Alcalde D, Bhatt $H$, Anver M, Bhat N, Nagashima K, Stewart CL \& Burke B (1999). Loss of A-type lamin expression compromises nuclear envelope integrity leading to muscular dystrophy. Journal of Cell Biology, 147: 913-920.

31. Farrell FX, Sax CM \& Zehner ZE (1990). A negative element involved in vimentin gene expression. Molecular and Cellular Biology, 10: 2349-2358

32. Guma FCR, Mello TG, Mermelstein CS, Fortuna VA, Wofchuk ST, Gottfried C, Guaragna RM, Costa ML \& Borojevic R (2001). Intermediate filament modulation in an in vitro model of the hepatic stellate cell activation or conversion into the lipocyte phenotype. Biochemistry and Cell Biology, 79: 409-417.

33. Kachinsky AM, Dominov JA \& Miller JB (1994). Myogenesis and the intermediate filament protein, nestin. Developmental Biology, 165: 216-228. 
34. Granger BL \& Lazarides E (1980). Synemin: a new high molecular weight protein associated with desmin and vimentin filaments in muscle. Cell, 22: 727-738.

35. Bellin RM, Huiatt TW, Critchley DR \& Robson RM (2001). Synemin may function to directly link muscle cell intermediate filaments to both myofibrillar Z-lines and costameres. Journal of Biological Chemistry, 276: 32330-32337.

36. Hirako $Y$, Yamakawa $H$, Tsujimura $Y$, Nishizawa $Y$, Okumura $M$, Usukura J, Matsumoto $H$, Jackson KW, Owaribe $K$ \& Ohara $O$ (2003). Characterization of mammalian synemin, an intermediate filament protein present in all four classes of muscle cells and some neuroglial cells: co-localization and interaction with type III intermediate filament proteins and keratins. Cell and Tissue Research, 313: 195-207.

37. Breckler J \& Lazarides E (1982). Isolation of a new high molecular weight protein associated with desmin and vimentin filaments from avian embryonic skeletal muscle. Journal of Cell Biology, 92: 795806.

38. Schweitzer SC, Klymkowsky MW, Bellin RM, Robson RM, Capetanaki $Y$ \& Evans RM (2001). Paranemin and the organization of desmin filament networks. Journal of Cell Science, 114: 10791089.

39. Mizuno Y, Thompson TG, Guyon JR, Lidov HG, Brosius M, Imamura M, Ozawa E, Watkins SC \& Kunkel LM (2001). Desmuslin, an intermediate filament protein that interacts with $\alpha$-dystrobrevin and desmin. Proceedings of the National Academy of Sciences, USA, 98: 6156-6161.

40. Titeux M, Brocheriou V, Xue Z, Gao J, Pellissier JF, Guicheney P, Paulin D \& Li Z (2001). Human synemin gene generates splice variants encoding two distinct intermediate filament proteins. European Journal of Biochemistry, 268: 6435-6449.

41. Newey SE, Howman EV, Ponting CP, Benson MA, Nawrotzki R, Loh NY, Davies KE \& Blake DJ (2001). Syncoilin, a novel member of the intermediate filament superfamily that interacts with $\alpha$-dystrobrevin in skeletal muscle. Journal of Biological Chemistry, 276: 66456655.

42. Larsen TH, Dalen H, Sommer JR, Boyle R \& Lieberman M (1999). Membrane skeleton in cultured chick cardiac myocytes revealed by high resolution immunocytochemistry. Histochemistry and Cell Biology, 112: 307-316.

43. Bang ML, Gregorio C \& Labeit S (2002). Molecular dissection of the interaction of desmin with the C-terminal region of nebulin. Journal of Structural Biology, 137: 119-127.

44. Price MG (1987). Skelemins: cytoskeletal proteins located at the periphery of M-discs in mammalian striated muscle. Journal of Cell Biology, 104: 1325-1336.

45. Wiche G (1998). Role of plectin in cytoskeleton organization and dynamics. Journal of Cell Science, 111: 2477-2486.

46. Helfand BT, Mikami A, Vallee RB \& Goldman RD (2002). A requirement for cytoplasmic dynein and dynactin in intermediate filament network assembly and organization. Journal of Cell Biology, 157: 795-806.

47. Li H, Choudhary SK, Milner DJ, Munir MI, Kuisk IR \& Capetanaki Y (1994). Inhibition of desmin expression blocks myoblast fusion and interferes with the myogenic regulators MyoD and myogenin. Journal of Cell Biology, 124: 827-841.

48. Wang Q, Tolstonog GV, Shoeman R \& Traub P (2001). Sites of nucleic acid binding in type I-IV intermediate filament subunit proteins. Biochemistry, 40: 10342-10349.

49. Horwitz J (2003). Alpha-crystallin. Experimental Eye Research, 76: 145-153.

50. Chen F, Chang R, Trivedi M, Capetanaki Y \& Cryns VL (2003). Caspase proteolysis of desmin produces a dominant-negative inhibitor of intermediate filaments and promotes apoptosis. Journal of Biological Chemistry, 278: 6848-6853.

51. Goll DE, Thompson VF, Li H, Wei W \& Cong J (2003). The calpain system. Physiological Reviews, 83: 731-801.

52. Goldfarb LG, Vicart P, Goebel HH \& Dalakas MC (2004). Desmin myopathy. Brain, 127: 723-734.

53. Wang SM, Huang YS, Wu JC \& Tseng YZ (2000). Role of desmin filaments in chicken cardiac myofibrillogenesis. Journal of Cellular Biochemistry, 77: 635-644.

54. Tolstonog GV, Sabasch M \& Traub P (2002). Cytoplasmic intermediate filaments are stably associated with nuclear matrices and potentially modulate their DNA-binding function. DNA and Cell Biology, 21: 213-239

55. Hutchison CJ (2002). Lamins: building blocks or regulators of gene expression? Nature Reviews. Molecular Cell Biology, 3: 848-858.

56. Milner DJ, Mavroidis M, Weisleder N \& Capetanaki Y (2000). Desmin cytoskeleton linked to muscle mitochondrial distribution and respiratory function. Journal of Cell Biology, 150: 1283-1298.

57. Mermelstein CS, Costa ML, Chagas Filho C \& Moura Neto V (1996). Intermediate filament proteins in TPA-treated skeletal muscle cells in culture. Journal of Muscle Research and Cell Motility, 17: 199206.

58. Mermelstein CS, Portilho DM, Medeiros RB, Matos AR, EinickerLamas M, Tortelote GG, Vieyra A \& Costa ML (2004). Cholesterol depletion by methyl-b-cyclodextrin enhances myoblast fusion and induces the formation of myotubes with disorganized nuclei. Cell and Tissue Research (in press).

59. Shah SB, Davis J, Weisleder N, Kostavassili I, McCulloch AD, Ralston E, Capetanaki Y \& Lieber RL (2004). Structural and functional roles of desmin in mouse skeletal muscle during passive deformation. Biophysical Journal, 86: 2993-3008.

60. Fuchs $\mathrm{E}$ (1996). The cytoskeleton and disease: genetic disorders of intermediate filaments. Annual Review of Genetics, 30: 197-231.

61. Colucci-Guyon E, Portier MM, Dunia I, Paulin D, Pournin S \& Babinet C (1994). Mice lacking vimentin develop and reproduce without an obvious phenotype. Cell, 79: 679-694. 